\title{
MONTE CARLO METHOD AND CAUCHY MODEL: IDENTIFYING CHALK LAYER DENSITY ON RIVNE NPP
} INDUSTRIAL AREA

The paper furthers the theory and methods of random process and field statistical simulation (Monte Carlo methods) based on spectral decomposition, and focuses on the application of the methods mentioned to environmental geophysical monitoring.

A new effective statistical technique has been devised to simulate random fields in 3D space for chalk layer density on the Rivne NPP industrial site. There has been solved the problem of statistical simulation of "noise" for chalk layer density realizations as random fields in $3 D$ space.

$2 D$ data were selected from 3D data on chalk layer density at three depth levels (28, 29, $30 \mathrm{~m}$ below the surface). The data were presented as the sum of deterministic and random components for each level. Deterministic 2D trend surface was constructed using spline interpolation. The random component ("noise" factor) is a 2D homogeneous isotropic random field.

There has been formulated an algorithm to generate "noise" field realization for chalk layer density involving Cauchy correlation function, which has been devised on the mean-square approximation of random fields' estimator. There has been made a statistical model for Gaussian homogeneous and isotropic random fields in three-dimensional space, which were given by their statistical characteristics.

There has been made Spectr 3 program based on the chosen statistical model and the formulated algorithm for statistical simulation of $3 D$ random fields' realizations. Additionally simulated have been 300 values in the intervals between observation points for each level. The effective comparison of error simulation between the method proposed and TBM (turning band method) has been made.

There has been introduced a method of random processes and fields in 3D space statistical simulation based on spectral decompositions in order to enhance map accuracy by the example of chalk layer density data. There has been developed a universal method of statistical simulation of geophysical data for generating random 3D fields' realizations on grids with required accuracy and regularity.

Key words: environmental geophysical monitoring, chalk layer, statistical model.

3. Выжва, д-р физ.-мат. наук, доц., zoya_vyzhva@ukr.net

В. Демидов, канд. физ.-мат. наук, ассистент, fondadl@ ukr.net

А. Выжва, асп., motomustanger@ukr.net

Киевский национальный университет имени Тараса Шевченко

Геологический факультет, ул. Васильковская, 90, г. Киев, 03022, Украина

\section{ИССЛЕДОВАНИЕ ПЛОТНОСТИ МЕЛОВОЙ ТОЛЩИ МЕТОДОМ МОНТЕ-КАРЛО НА ПРОМПЛОЩАДКЕ РО- ВЕНСКОЙ АЭС С ПРИМЕНЕНИЕМ МОДЕЛИ КОШИ}

Работа посвящена разработке теории и методов статистического моделирования моделирования (методов Монте-Карло) случайных процессов и полей на основе их спектральных разложений, а также применению таких методов к решению актуальных задач геофизического моніиторинга окружающей среды. Для данных исследования плотности толщи меловых отложений на территории промплощадки Ровенской АЭС разаботано новую еффективную методику численного моделирования случайных 3D полей. Рассмотрено задачу статистического моделирования реализаций случайного поля “шума” для данных плотности меловой толщи в трёхмерном пространстве.

Из 3D данных плотности меловой толщи было выделено 2D данные на трёх уровнях глубины залегания пород (28, 29, 30 м от поверхности). На каждом уровне данные были представлены в виде суммы детерминированной и случайной составляющих. Детерминироованая 2D трендовая поверхность была построена при помощи сплайновой интерполяции. Случайная составляющая (так званный «шум») - это однородное изотропное 2D случайное поле.

Сформулирован алгоритм для генерирования реализаций случайного поля “шума” для данных плотности меловой толщи с корреляционной функцией типа Коши на основе оценки среднеквадратической аппроксимации рассматриваемых случайных полей. Сконструирована статистическая модель для гауссовских однородных изотропных случайных полей в в трёхмерном пространстве, которые заданы своими статистическими характеристиками.

На основе подобранной статистической модели и разработаного алгоритма построено оригинальную программу Spectr 3 для численного моделирования реализаций значений данных в трёхмерном случае. Дополнительно смоделированы 300 симитированных значений данных плотности меловой толщи в промежутках между точками наблюдений для каждого уровня. Проведено эффективное сравнение точности моделирования предложенного метода и меmoda TBM (turning band method).

Ведрён метод статистического моделирования реализаций случайных 3D полей на основе спектральных разложений в решение проблем кондиционности карт путём дополнения данных плотности меловой толщи до необходимой детальности. Разработан универсальный метод численного геофизических данных, который даёт возможность решить проблемы генерирования реализаций случайных полей в трёхмерном пространстве на сетке необходимой детальности и регулярности.

Ключевые слова: геофизический мониторинг природных процессов, меловые породы, статистическое моделирование.

УДК 624.131

Н. Аксьом, канд. геол. наук, мол. наук. співроб., E-mail: axmn@i.ua Київський національний університет імені Тараса Шевченка Геологічний факультет, вул. Васильківська, 90, м. Київ, 03022, Україна

\section{ТРИВИМІРНЕ МОДЕЛЮВАННЯ ПРИ РОЗРАХУНКАХ СТІЙКОСТІ СХИЛІВ 3 ВИКОРИСТАННЯМ ГІС (НА ПРИКЛАДІ М. КИЄВА)}

(Рекомендовано членом редакційної колееії д-ром геол. наук, доц. О.є. Кошляковим)

У статті наведено дані про зсувні процеси в м. Києві, розелянуто метод тривимірної оцінки стійкості схилів з використанням ГІС. Репрезентативною ділянкою досліджень обрано зсувні схили пагорбу Андріївської церкви в м. Києві. Наведено результати розрахунків коефіцієнтів стійкості класичним двовимірним методам К. Терцагі та тривимірним методом Ховланда. 
В Києві зафріксовано близько 100 активних зсувів та 6 зсувних рельєфів. Більшість зсувів перебуває у стадії тимчасової стабілізації за рахунок роботи протизсувних споруд. Інтенсивність зсувного процесу зростає разом з освоєнням схилів і проведенням на них невпорядкованого будівництва.

Розвиток потужних яружних систем супроводжувався складними переміщеннями великих обсягів ґрунтів на бортах ярів та по їх тальвегах. У такому переміщенні на різних ділянках яружної системи відбуваються рухи різного характеру -від зсувів до обвалів ґрунту.

В загальному випадку при оцінці розвитку зсувів на схилах і укосах необхідно враховувати можливість порушення як загальної, так і місцевої стійкості

Зараз активно розвивається і застосовується у розрахунках стійкості схилів тривимірне моделювання (3D). B даний час воно все більше входить в практику інженерних розрахунків, у тому числі в чисельне моделювання напружено-деформованого стану масивів ґрунтів, активно застосовується при вирішенні широкого спектра екологічних $і$ гідрогеологічних завдань.

Визначення величин коефіцієнтів стійкості здійснено на підставі розрахункової моделі стійкості К. Tерцагі (2D) та методом Ховланда (3D) для однієї з зсувних ділянок в м. Києві. Тривимірна оцінка стійкості зсувонебезпечних схилів засобами ГІС дозволить в подальшому використовувати отримані результати для моніторинеу їх стану та (в разі необхідності) проведенню запобіжних заходів для попередження зсувів.

Ділянка території, яка досліджувалась, приурочена до правого корінного схилу долини р. Дніпро і розташована поблизу підніжжя Андріївської гори. Геологічна будова ділянки території Андріївської церкви на глибину до 23 м представлена відкладами четвертинної та неогенової систем.

Результати розрахунків дозволили виділити на схилах пагорбу дві потенційні зони утворення зсувів - на північ $i$ на схід від Андріївської Церкви.

Тривимірна оцінка дозволяє більш об'єктивно оцінювати ризики, пов'язані з просторовою активізацією зсувного процесу.

Ключові слова: зсуви, коефіцієнт стійкості, тривимірна модель стійкості, метод Ховланда

Постановка проблеми у загальному вигляді. Місто Київ - одне з найбільших міст України, де негативні геологічні процеси поширені досить широко і спричиняють значні економічні та інші збитки в народногосподарській діяльності. Тут зафіксовано близько 100 активних зсувів та 6 зсувних рельєфрів. Більшість зсувів перебуває у стадії тимчасової стабілізації за рахунок роботи протизсувних споруд. Інтенсивність зсувного процесу зростає разом з освоєнням схилів і проведенням на них невпорядкованого будівництва. Активізація зсувного процесу відмічена на ділянках зсувного схилу між вул. Петровською та Кудрявською (Петровський яр), біля Андріївської церкви, між вул. Дехтярівською та Киянківським провулком, в районі фунікулера, нижче від Маріїнського палацу, біля пам'ятника Магдебурзькому праву та на території Києво-Печерської Лаври. Більшість зсувів приурочена до правого більш крутого берегу р. Дніпро. До найбільш зсувонебезпечних схилів, де можлива активізація процесу, відносяться ділянки між вулицями Лук'янівська - Олегівська, Глибочицька Петровська (Гончарний яр, Петровський яр) та район Видубицького монастиря.

У м. Києві зсуви проявляються як ерозійногравітаційні процеси на високих правобережних схилах долини Дніпра та схилах його правобережних допливів з охопленням палеоген-неогенових і четвертинних відкладів [3]. Розвиток зсувів обумовлений багатьма чинниками, серед яких найважливіші - впливи гідрометеорологічних процесів в умовах антропогенних порушень рослинного покриву, поверхневого та підземного стоків. Максимум зсувної активності приходиться на періоди, коли активно проявлялись ерозійні процеси, особливо навесні при таненні снігу, влітку під час злив.

Розвиток потужних яружних систем супроводжувався складними переміщеннями великих обсягів ґрунтів на бортах ярів та по їх тальвегах. В такому переміщенні на різних ділянках яружної системи відбуваються рухи різного характеру - від зпливів до зсувів і обвалів ґрунту.

Аналіз досліджень ерозійно-гравітаційних процесів на схилах долин Дніпра та його допливів, які проведені в різні роки $[1,8]$ став підставою для узагальнення, що деякі зсуви тут мали характер зпливів ґрунту (глетчерів) і відбувалися за відсутності дерево-чагарникової рослинності або пригніченої трав'яної.

У загальному випадку при оцінці розвитку зсувів на схилах і укосах необхідно враховувати можливість порушення як загальної, так і місцевої стійкості $[2,5]$. Під оці- нкою стійкості при цьому розуміється визначення можливості появи та ступеня розповсюдження активних (рухаючих) зсувів при тих інженерно-геологічних умовах та діючих навантаженнях, що спостерігаються в реальних обставинах при виконанні пошуків (досліджень) на зсувних чи зсувонебезпечних ділянках схилів чи укосів [7]

Виділення невирішених раніше частин загальної проблеми. Зараз активно розвивається і застосовується у розрахунках стійкості схилів тривимірне моделювання (3D). На даний час воно все більше входить у практику інженерних розрахунків, у тому числі в чисельне моделювання напружено-деформованого стану масивів ґрунтів, активно застосовується при вирішенні широкого спектра екологічних і гідрогеологічних завдань. Одним з останніх «оплотів» використання в інженерній геології методів, заснованих на двовимірному аналізі (2D), залишалися розрахунки стійкості схилів. Проте останнім часом і в цій області позиції 2D моделювання достатньо похитнулися. На теперішній час розроблено велику кількість методів тривимірних розрахунків стійкості на основі концепції граничної рівноваги і механіці суцільного середовища.

Метою роботи $є$ тривимірна оцінка стійкості зсувонебезпечних схилів в м. Києві засобами ГІС з подальшим використанням отриманих результатів для моніторингу їх стану та (в разі необхідності) проведенню запобіжних заходів для попередження зсувів.

Виклад основного матеріалу. Перший досвід створення просторових методів розрахунку стійкості схилів відноситься до кінця 60-х років минулого століття, але тільки в останні роки 3D методи в розрахунку стійкості схилів стали активно використовуватися для вирішення практичних завдань. Багато виробників спеціалізованого програмного забезпечення вже мають програмні модулі по тривимірному моделюванню стійкості схилів.

При цьому, розширення аналізу при розрахунку стійкості схилів у плоскій постановці до об'ємних рішень не таке просте завдання, як просто додавання ще одного виміру. Моделювання стійкості схилів у тривимірному варіанті безперечно більш правильно і перспективно в порівнянні 3 двомірними моделями, а переваги, пов'язані з об'ємним аналізом , очевидні. Вкажемо на деякі з них [4].

По-перше, в тривимірній постановці поверхня ковзання моделюється (за умови однорідності властивостей ґрунтів) у вигляді сегмента еліпсоїдального поверхні. Круглоциліндрична поверхня ковзання при розрахунку в двомірному варіанті не $є$ її аналогом. 3 точки зору 
механіки, розглянута задача, не може вважатися плоскою i, як наслідок, не може коректно, без істотних припущень, розв'язуватися в двомірній постановці.

По-друге, навіть у разі допустимості застосування двомірного варіанту при розрахунку стійкості схилів, існує велика кількість умов, які необхідно виконувати при вирішенні завдання, наприклад, таких як однорідність геологічної будови і топографічна однорідність схилу в напрямку його простягання. Але в практиці існує безліч випадків, коли саме ці фрактори будуть чинити істотний вплив на стійкість (наприклад, тектонічний розлом, що перетинає схил під кутом або зрізка частині схилу при будівництві доріг і трубопроводів). Усе це можна врахувати тільки при побудові тривимірної моделі.

Розглянемо приклад просторового моделювання стійкості схилів.

Метод Х.Д. Ховланда (Hovland). Метод, який розробив Ховланд [11], є розширенням в третій вимір припущень двовимірного методу Фелленіуса. Замість плас- тин в цьому методі були використані колони. У методі Ховланда зсувні сили між пластинами, що діють з боків колони, ігноруються. Нормальні і зсувні сили, що діють на основу кожної колони, виходять як компоненти ваги колони. Ще одне припущення полягає в тому, що існує рух тільки в одному напрямку, і рівновага системи розраховується на цей напрямок.

Тривимірний коефіцієнт стійкості визначається як відношення загальної суми утримують сил вздовж поверхні зсуву до суми сил, що зсувають.

Коефріцієнт стійкості схилу може визначатись наступним чином:

$$
\mathrm{K}_{\mathrm{c} \mathrm{T}}=\frac{\sum M_{y m}}{\sum M_{3 c}}
$$

Розрахункова схема методу Ховланда показана на рис. 1.

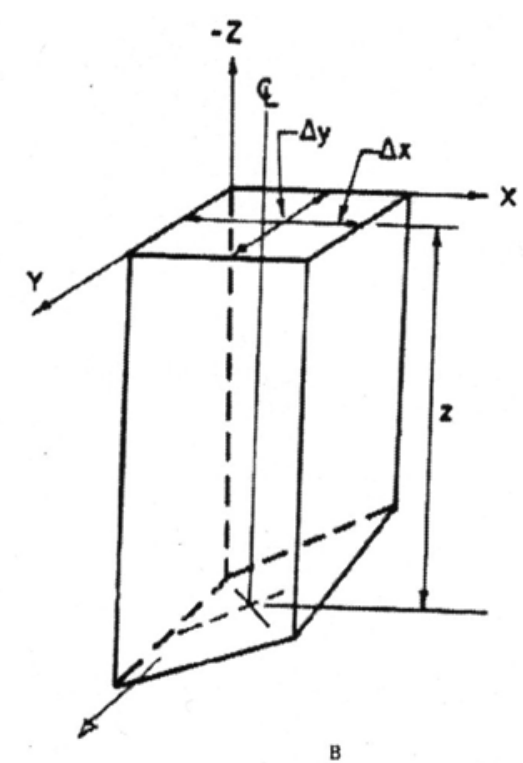

Рис. 1. Схема розрахунку за методом Ховланда: a - план, б - розрізи, в - тривимірний вид стовпчика порід

Було прийнято, що координати X і У перпендикулярні одна одній в горизонтальній площині, координата Z вертикальна, і вісь У направлена в бік руху зсувного тіла (вниз по схилу). Розміри стовпчика в горизонталь- ній площині визначаються величинами $\Delta \mathrm{x}$ і $\Delta y$. Припускаючи, що $\Delta x$ і $\Delta y \epsilon$ постійними для всіх стовпців (сітка розбиття рівномірна), коефіцієнт стійкості може бути розрахований таким чином:

$$
\mathrm{K}_{\text {ст }}=\frac{\mathrm{M}_{\text {утрим }} \times \cos \theta_{\text {avr }}}{\mathrm{M}_{\text {зсув }} \times \sin \theta_{\text {avr }} \cos \theta_{\text {avr }}}=\frac{\sum_{\mathrm{j}} \sum_{\mathrm{i}}\left(\mathrm{c} \mathrm{A}+\left[\mathrm{z}_{\mathrm{ji}} \gamma \cos \theta-\mathrm{u}_{\mathrm{ji}}\right] \operatorname{tg} \varphi\right) \cos \theta_{\text {avr }}}{\sum_{\mathrm{j}} \sum_{\mathrm{i}} \mathrm{z}_{\mathrm{ij}} \gamma \cdot \sin \theta_{\text {avr }} \cdot \cos \theta_{\text {avr }}}
$$

де у та z - об'ємна вага стовпчика ґрунту та глибина залягання поверхні ковзання (параметри, що визначають величину тиску стовпчиків ґрунту від власної ваги); А - площа розрахункового стовпчика; $\varphi$ - кут внутрішнього тертя та $c$ - питоме зчеплення ґрунту; $\theta_{\text {avr }}$ та $\theta$ відповідно, кут видимого падіння схилу та крутизна схилу (параметри, що визначають просторову орієнтацію схилу); $i$ та $j$ - відповідно, номер рядку та колонки матриці стовпчиків зсувного тіла.

Ховланд встановив, що кожне співвідношення зчеплення і кута внутрішнього тертя порід може мати свою власну критичну поверхню зсуву і геометрію. Дослідження також показали, що ставлення коефіцієнтів стійкості в двомірному і тривимірному випадку досить чутливо до міцносних показників порід, а також до фрорми поверхні ковзання і відносно нечутливі до ширини зсувної поверхні. Так само, отримані ним результати показали, що тривимірні коефіцієнти стійкості, як правило, вище, ніж двовимірні, хоча в деяких ситуаціях, в незв'язних ґрунтах тривимірний коефріцієнт стійкості може бути нижче двовимірного.

Запропонована формула дозволяє розглядати зсувний масив як такий, що складається не з одного ряду стовпчиків (як у плоскій задачі), а з цілої матриці останніх. Одним із найбільш розповсюджених інструментів оцінки зсувної небезпеки на основі ГІС-технології є підхід, який базується на сітковій трьохмірній моделі. Таке тривимірне представлення розрахунку коефіцієнту стійкості схилу дозволяє застосовувати його в сучасних ГIC. Кожен з параметрів формули, використовуючи набір інструментів просторового аналізу програми ArcGIS 9.3, можна представити у вигляді grid-поверхні - растрового шару, кожному пікселу якого присвоюється конкретне значення в діапазоні значень обраного параме- 
тру. А отже, будь-який розрахунковий стовпчик тримірної моделі Ховланда може бути представлений у вигляді піксела.

Важливо відмітити, що в якості базової моделі розрахунку стійкості може бути використано будь-який метод граничної рівноваги.

Для випадку коли в масиві зсувного тіла присутня природна поверхня ковзання, розрахунок ведеться таким чином:

а) за матеріалами топографічної зйомки та інженерно-геологічних вишукувань, проведених на зсувному схилі, складають цифрову модель рельєфу (ЦМР) і поверхні ковзання зсуву, визначають розрахункові значення фрізико-механічних властивостей ґрунтів, що відповідають їх природному стану на момент дослідження у зоні зсуву;

б) у ГІС виконують графрічне віднімання ЦМР денної поверхні і поверхні ковзання зсуву. В результаті цього отримують нову цифрову модель потужності зсуву;

в) графічним диференціюванням поверхні ковзання зсуву отримують ще одну цифрову модель - ухилів поверхні ковзання;

г) у ГІС зсувне тіло розбивається на ряд елементарних призм, при цьому приймається, що в межах кожної призми зберігається постійним кут нахилу поверхні ковзання;

д) за числовими значеннями кутів падіння поверхні ковзання а, вертикальної потужності зсуву $h$, об'ємної ваги ґрунтів $\gamma$, площі основи призм $S$ і зсувних характеристик ґрунтів $\varphi$ і с.

Даний підхід дозволяє провести оціночний аналіз стійкості схилу при об'ємній постановці задачі. Проте він не враховує багато факторів, наприклад, зсувні сили, що діють на гранях призми, просторову зміну кута падіння поверхні ковзання а, вплив ґрунтових вод і т.ін. Тому стало доцільним розглянути тривимірний розрахунок коефіцієнту запасу стійкості зсуву за методом Ховланда.

Визначення величин коефріцієнтів стійкості здійснено на підставі розрахункової моделі стійкості К. Терцагі (2D) та методом Ховланда (3D) для однієї з зсувних ділянок в м. Києві.

Ділянка території, яка досліджувалась, приурочена до правого корінного схилу долини р. Дніпро і розташована поблизу підніжжя Андріївської гори, що знаходиться над рівнем річки приблизно на 80 м.

На Андріївському пагорбі у 1767 р було побудовано Андріївський собор, який є пам'ятником архітектури XVIII ст. Собор представляє собою двоповерхову споруду із цегли у вигляді цоколя 3 розмірами в плані $37 \times 30$ м та безпосередньо церкву з великим куполом в центрі і чотирма стрілчатими баштами і колонами по кутах. Позначки закладання складного по висоті і в плані фундаменту змінюються від 166,89 м (у районі північно-західного фасаду) до 170,56 м (на відрізку південносхідної торцевої стіни).

Церква розташована на високому пагорбі на правому березі Дніпра, там де раніше знаходився бастіон Старокиївської фортеці. Побудована вона у виключно складних інженерно-геологічних умовах і 3 великою майстерністю вписана в рельєф місцевості.

Геологічна будова ділянки території Андріївської церкви на глибину до 23 м представлена відкладами четвертинної та неогенової систем.

У покрівлі четвертинних утворень практично повсюдно поширені насипні ґрунти. Ці ґрунти спільно з давньозміщеними утворюють зони ґрунтів потужністю до 10 м, зміщення яких не виключено в майбутньому. Стратиграфічно нижче залягає супісок лесовидний (мі- сцями повністю розмитий) потужністю до 9,8 м. У підошві його де не де спостерігається лінзи суглинку флювіогляціального з включенням малопотужних лінз супіску та піску. Сумарна потужність флювіогляціальних відкладів не перевищує 3,4 м.

Суглинок моренний з тонкими прошарками супіску та піску, а також включеннями гальки кристалічних порід, розвинутій на більшій частині ділянки, що розглядається, і його потужність сягає 9,2 м.

Аналогічним поширенням характеризується глина бура, покрівля якої на більшій частині ділянки території розмита. Її максимальна потужність з урахуванням лінз прісноводного суглинку досягає 9,8 м.

Розкрита потужність повсюдно розвинутих строкатих глин досягає 3,7 м, а глин полтавського горизонту - 1,5 м.

Протягом всієї своєї історії Андріївська церква та прилегла до неї територія зазнавала деформацій та руйнувань. У зв'язку з частими зсувами та опливанням зараз до $50-55^{0}$ збільшилась крутизна раніше більш пологих схилів пагорбу. Верхня частина його укосу щільно примикає до краю паперті і на східній ділянці оголив підпірну конструкцію.

Розрахунки стійкості схилів пагорбу показали, що у всіх випадках найбільш послаблені поверхні ковзання проходили в корінних породах на контактах з бурими або строкатими глинами. Отже, утворення зсувів мало переважно глибинний характер.

Результати розрахунків дозволили виділити на схилах пагорбу дві потенційні зони утворення зсувів - на північ і на схід від Андріївської Церкви. Коефріцієнти запасу стійкості укосів за методом Ховланда $\left(K_{\mathrm{cт}}\right)$ в цих зонах змінюються від 0,96-1,14 (східне підніжжя пагорбу) і від 0,9 до 1,21 (північно-східне підніжжя), що нижче нормативних значень для споруд 1-го класу $\left(K_{\mathrm{cт}}=1,25-\right.$ 1,35). Отримані величини коефріцієнтів стійкості за розрахункової схемою К.Терцагі становлять 1,62-1,82. Для цих зон характерним $€$ досить високе положення РГВ та велика крутизна укосів. Їх довготривала стійкість не може бути забезпечена без спеціальних заходів

Висновки. Важливою перевагою тривимірної оцінки стійкості схилів $є$ той факт, що такий розрахунок дозволяє прогнозувати розвиток зсувного процесу не тільки по глибині проникнення (у масиві), але і в плані. При цьому може вирішуватися завдання по знаходженню найменш стійкою області на зсувонебезпечному схилі. Це дозволяє більш об'єктивно оцінювати ризики, пов'язані 3 просторовою активізацією зсувного процесу, приймати більш обґрунтовані конструктивні рішення по протизсувному захисту. Проведені співставлення і кількісний аналіз величин коефіцієнтів стійкості зсувонебезпечної ділянки схилу за розрахунковими схемами К. Терцагі та Ховланда підтвердили це положення.

\section{Список використаних джерел:}

1. Геоинформатика / А.Д. Иванников, В.П. Кулагин, А.Н. Тихонов, В.Я. Цветков, (2001). М.: МаксПресс, 349 с.

Ivannikov A.D., Kulagin V.P., Tihonov A.N., Tsvetkov V.Ya., (2001). Geoinformatika. Moskow: MaksPress, 349 p. (In Russian).

2. Дранников А.М., (1964). Противооползневые сооружения и мероприятия для защиты городской территории. Матер. совещания по вопросам оползней и мер борьбы с ними. Изд-во Киевского унивеситета, 42-56.

Drannikov A.M., (1964). Protivoopolznevyie sooruzheniya i meropriyatiya dlya zaschityi gorodskoy territorii. Materialyi soveschaniya po voprosam opolzney i mer borbyi s nimi. Izd-vo Kievskogo univesiteta, 42-56 (In Russian).

3. Звіт обґрунтування зсувних і зсувонебезпечних ділянок. Карта-схема зсувних процесів в м. Києві 3 виділенням найбільш небезпечних ділянок (том 3), (2001). Київ, 603 с. 
Zvlt obgruntuvannya zsuvnih I zsuvonebezpechnih dllyanok. Karta-shema zsuvnih protsesiv $v \mathrm{~m}$. Kievi $\mathrm{z}$ vidilennyam naybllsh nebezpechnih dllyanok (tom 3), (2001). Kyiv, 603 p. (In Ukrainian).

4. Зеркаль О.В., Фоменко И.К., (2011). Рудник будущого: проекти, технологии, оборудование. Сопоставимость двухи трёхмерного анализа устойчивости склонов. Пермь, 1, 46-49.

Zerkal O.V., Fomenko I.K., (2011). Rudnik buduschogo: proekti, tehnologii, oborudovanie. Sopostavimost dvuh- $i$ tryohmernogo analiza ustoychivosti sklonov. Perm., 1, 46-49 (In Russian).

5. Котлов Ф.В., Брашнина И.А., Сипягина И.К., (1967) Город и геологические процессы. М.: Наука, 226 с.

Kotlov F.V., Brashnina I.A., Sipyagina I.K., (1967). Gorod i geologicheskie protsessyi. Moskow, Nauka, 226 p. (In Russian).

6. Лічков Л.С., (1938). До питання про режим зсувних явищ в районі розташування м. Києва та його околиць. Геологічний журнал, 5, 4, 146-195.

LIchkov L.S., (1938). Do pitannya pro rezhim zsuvnih yavisch $v$ rayonl roztashuvannya m. Kieva ta yogo okolits. Geologlchniy zhurnal, 5, 4, 146-195 (In Ukrainian).
7. Науково-технічний звіт про роботу по темі: „Укріплення пагорбу Андріївської церкви. Матеріали попередніх досліджень та вишукувань”, (2002). К: ВАТ „Київпроект» інститут „Київінжпроект”, 23 с.

Naukovo-tehnlchniy zvit pro robotu po temi: „Ukrlplennya pagorbu Andrlyivskoyi tserkvi. Materlali poperednih doslidzhen ta vishukuvan”, (2002). Kyiv: VAT „Kiyivproekt» Institut "KiyivInzhproekt", 23 p. (In Ukrainian).

8. Оползни. Исследование и укрепление / Под редакцией Р. Шустера и Р. Кризека, (1981). М.: Мир, 368 с.

Opolzni. Issledovanie i ukreplenie. In ed. R. Shustera, R. Krizeka, (1981). Moskow: Mir, 368 p. (In Russian).

9. Albataineh N., (2006). Slope stability analysis using 2D and 3D methods. Ohio, United States: The University of Akron, $126 \mathrm{p}$.

10. Cavounidis S., (1987). On the ratio of factor of safety in slope stability analyses. Geothnique, 37, 2, 207-210.

11. Hovland H.J., (1977). Three-dimensional slope stability analysis method. Journal of the Geotechnical Engineering. Division Proceedings of the American Society of Civil Engineers, 103, 971-986.

Надійшла до редколегії 22.04.14.

N. Aksyom, Cand. Sci. (Geol.), Research Associate,

E-mail: axmn@i.ua

Geological Faculty, Taras Schevchenko National University of Kyiv

90, Vasylkivska Str., Kyiv, 03022 Ukraine

\section{GIS IN COMPUTING KYIV SLOPES STABILITY: THREE-DIMENSIONAL MODELING}

The paper reports on landslide processes in Kyiv, and focuses on GIS methods in three-dimensional assessment of slope stability. Sliding hillsides of St. Andrew's Church in Kyiv make an area of study. The paper presents computation of the slope stability factor based on $K$. Tertsahi classical two-dimensional method and Hovland's three-dimensional method.

There have been recorded about 100 active landslides and 6 sliding reliefs in Kyiv. Most landslides have been temporarily stabilized by engineering constructions. However, landsliding increases because of unregulated property development on the slopes. The development of deep ravines is accompanied by complex movements of soil masses on the sides of ravines and on their bottoms resulting in landsliding or slumping. In general, to estimate a threat of landsliding there should be considered a scale of local and general slope destabilization.

Three-dimensional modelling (3D) is widely used to calculate slope stability. At present, it is becoming essential in engineering calculations, with numerical simulation of the soil mass strain being applied to solve a wide range of environmental and hydrogeological problems.

Stability factor for the investigated landslide site has been computed on (2D) sustainability model by $K$. Tertsahi and (3D) Hovland's method. The GIS 3D method to assess stability of the landslide-prone slopes provides their further monitoring, for landslide preventive measures to be taken when necessary.

The site under study makes a base slope of the Dnieper valley and is located at the foot of St. Andrew's hill. The geological structure of the investigated area is represented by the Quaternary and Neogene sediments to a depth of $23 \mathrm{~m}$. Computation reveals two landslide-prone slopes, to the north and to the east of St. Andrew's Church. Three-dimensional spatial assessment enhances the accuracy of predicting landslide risks.

Key words: landslides, stability factor, three-dimensional stability model, Hovland's method.

Н. Аксьом, канд. геол. наук, младший научный сотрудник, ахтn@i.ua

Киевский национальный университет имени Тараса Шевченко

Геологический факультет, ул. Васильковская, 90, г. Киев, 03022, Украина

\section{ТРЕХМЕРНОЕ МОДЕЛИРОВАНИЕ ПРИ РАСЧЕТАХ УСТОЙЧИВОСТИ СКЛОНОВ С ИСПОЛЬЗОВАНИЕМ ГИС (НА ПРИМЕРЕ Г. КИЕВА)}

В статье представлены данные об оползнях в Киеве, рассмотрен метод трехмерной оценки устойчивости склонов с использованием ГИС. Репрезентативным участком исследований выбраны оползневые склоны холма Андреевской церкви в г.Киев. Приведены результаты расчетов коэффициентов устойчивости классическим двумерным методам К. Терцаги и трехмерным методом Ховланда.

В Киеве зафиксировано около 100 активных оползней и 6 сдвижных рельефов. Большинство оползней находится в стадии временной стабилизации за счет работы противооползневых сооружений. Интенсивность оползневого процесса растет вместе с освоением склонов и проведением на них неупорядоченного строительства.

Развитие мощных овражных систем сопровождался сложными перемещениями больших объемов грунтов на бортах оврагов и по их тальвегах. В таком перемещении на разных участках овражной системы происходят движения различного характера -- от оползней до обвалов почв. В общем случае при оценке развития оползней на склонах и откосах необходимо учитывать возможность нарушения как общей, так и местной устойчивости.

Сейчас активно развивается и применяется в расчетах устойчивости склонов трехмерное моделирование (3D). В настоящее время оно все больше входит в практику инженерных расчетов, в том числе в численное моделирование напряженно-деформированного состояния массивов грунтов, активно применяется при решении широкого спектра экологических и гидрогеологических задач.

Определение величин коэффициентов устойчивости осуществлено на основании расчетной модели устойчивости К. Терцаги (2D) и методом Ховланд (3D) для одной из оползневых участков в 2. Киев. Трехмерная оценка устойчивости оползневых склонов средствами ГИС позволит в дальнейшем использовать полученные результаты для мониторинга их состояния и (в случае необходимости) проведению мер для предупреждения оползней.

Участок территории исследований приурочен к правому коренному склону долины р. Днепр и расположен у подножия Андреевской горы. Геологическое строение участка территории Андреевской церкви на глубину до 23 м представлено отложениями четвертичной и неогеновой систем. Результаты расчетов позволили выделить на склонах холма две потенциальные зоны образования оползней - на север и на восток от Андреевской церкви. Трехмерная оценка позволяет более объективно оценивать риски, связанные с пространственной активизацией оползневого процесса.

Ключевые слова: оползни, коэффициент устойчивости, трехмерная модель устойчивости, метод Ховланда. 